\title{
Justice-Forward Course Design
}

\author{
Laura May Pipe \\ University of North Carolina Greensboro
}

\author{
Jennifer T. Stephens \\ University of North Carolina Greensboro
}

\begin{abstract}
With shifting societal and learner needs, expectations, and experiences, course design must evolve to best support students in both adapting to and creating change. By incorporating the Toward a Liberated Learning Spirit (TALLS) model into backward course design, courses can be designed to encourage intellectual risk-taking and attend to diverse knowledge and ways of knowing that disrupt oppressive and colonizing practices in both content and structure. This article outlines the use of the TALLS model in the backward design of a Native Movement undergraduate course to showcase how courses can be developed for engagement, inclusivity, and active and justice-forward learning.
\end{abstract}

Keywords: backward course design, engagement, inclusivity, active learning, social justice education

\section{INTRODUCTION}

Traditional approaches to course design often fail to include applied learning rooted in clearly defined principles and methods of direct action that are broad in both scope and depth of topical examination. These traditional approaches may even seek social justice outcomes without providing the space for students to practice justice-forward action or for educators to consider how their own identities impact student learning and engagement. Additionally, these approaches to course design fail to bridge students' natural curiosities, talents, and interests and course content and activities. According to Battiste (2010), centering learning around students' and educators' Learning Spirits - an essential curiosity brought into focus through reflection on one's personhood - encourages students' active participation in the learning process and the valuing of varied ways of knowing and knowledge sharing. Such connection with course material, educators, and peers is critical for the types of perspective-taking exercises, experiential simulations, and community-engaged projects that can move students from a detached and passive approach to learning to one that is immersive and consciousness-changing.

To create space for this connection building, we developed the Toward a Liberated Learning Spirit (TALLS) model (Pipe \& Stephens, 2019, 2021; Stephens \& Pipe, 2020) through a grounded theory approach that combines multiple theories and pedagogical approaches into a new model that bridges the gaps between the many and varied social justice theories and pedagogies while reconnecting learners with their Learning Spirits (Stephens \& Pipe, 2020). Through a backward design process that considers the intended learning outcomes alongside students' entry into the learning space-which is a history of detachment from their Learning Spirits and, thus, from the learning process - the use of the TALLS model 
in backward design offers a nonlinear framework for designing courses that support intellectual risk-taking and disrupt oppressive and colonizing practices present in our learning spaces.

\section{CHALLENGES OF TRADITIONAL APPROACHES TO COURSE DESIGN}

In an ever-evolving society, the academic and cultural experiences of our students continue to shift, necessitating the reevaluation of our approaches to course design and pedagogy. An obvious example is the shift in student expectations for learning after an extended period of remote or hybrid learning during the global health crisis brought about by COVID-19. In an information age, with access to self-guided classes, how-to videos, and knowledge sharing across multiple media platforms, students are looking for high levels of active engagement with content that is immediately resonant with their own interests and identities. With increased numbers of nontraditional students and diverse student populations, coupled with increased employer demand for soft skills such as critical thinking, communication, teamwork, digital literacy, and leadership (Mintz, 2020), educators need to approach course design with these shifting demographics and desired outcomes in mind.

Historically, course design followed a beginning-to-end, linear structure in which educators developed learning activities to teach predetermined content and assessments connected to the learning activities, followed by the evaluation of connections between these activities and assessments and the learning goals of the course (Bowen, 2017). This design at the course level often mapped onto the larger curriculum design at the institutional level, which has evolved from the classical Greek and medieval European models of intellectual arts and learning in grammar, rhetoric, and logic to models "representative of both educational and social experience, as a way of being in, understanding, and assessing a constantly changing world" ("Higher Education Curriculum," n.d.).

In the late 20th century, Wiggins and McTighe (1998) introduced backward design as an alternative approach to course design, putting learning - rather than instruction - at the center of the course design process. In backward design, educators begin with the desired learning outcomes for the course, develop formative and summative assessments that provide appropriate evidence of the desired learning outcomes, and then create learning activities that help to achieve the desired outcomes. By beginning with what students need to know and then considering how educators will know if students have met the desired outcomes and how to facilitate student learning toward these outcomes, backward design also attends to why, or the purpose behind every learning activity.

This approach solves a problem of intentionality and transparency in course design, ensuring that student learning is at the center of course development. However, backward design alone does not explicitly attend to changing student needs and diverse forms of knowledge and ways of knowing. Designing courses for engagement, inclusivity, and active and justice-forward learning, therefore, requires expanding the backward design process toward immersion and perspective-widening action. The TALLS model (Pipe \& Stephens, 2019, 2021; Stephens \& Pipe, 2020) provides an intentional framework for this expanded backward design process.

\section{BENEFITS OF USING THE TALLS MODEL IN COURSE DESIGN}

The Toward a Liberated Learning Spirit (TALLS) model (Pipe \& Stephens, 2019, 2021; Stephens \& Pipe, 2020; Figure 1) is predicated on the idea that, while modern pedagogy and course design function within colonizing educational structures, pedagogy and course design should also attempt to dismantle teaching and learning practices that privilege certain knowledge and ways of knowing. Moving clockwise from right to left, TALLS begins where students often enter higher education: in a place of detached learning where educators share knowledge that is passively received by learners. Anchored by reflection, courses designed through TALLS create space for diverse ways of knowing from inside and outside of the classroom community and for engaging in "creative tension" (King, 1963) that challenges students to move toward change (in thinking and doing). Facilitating an ongoing process of consciousness changing, the 
TALLS model is nonlinear and allows students to arrive at different levels of understanding at different times.

\section{FIGURE 1 \\ TOWARD A LIBERATED LEARNING SPIRIT (TALLS) MODEL FOR DEVELOPING CRITICAL CONSCIOUSNESS}

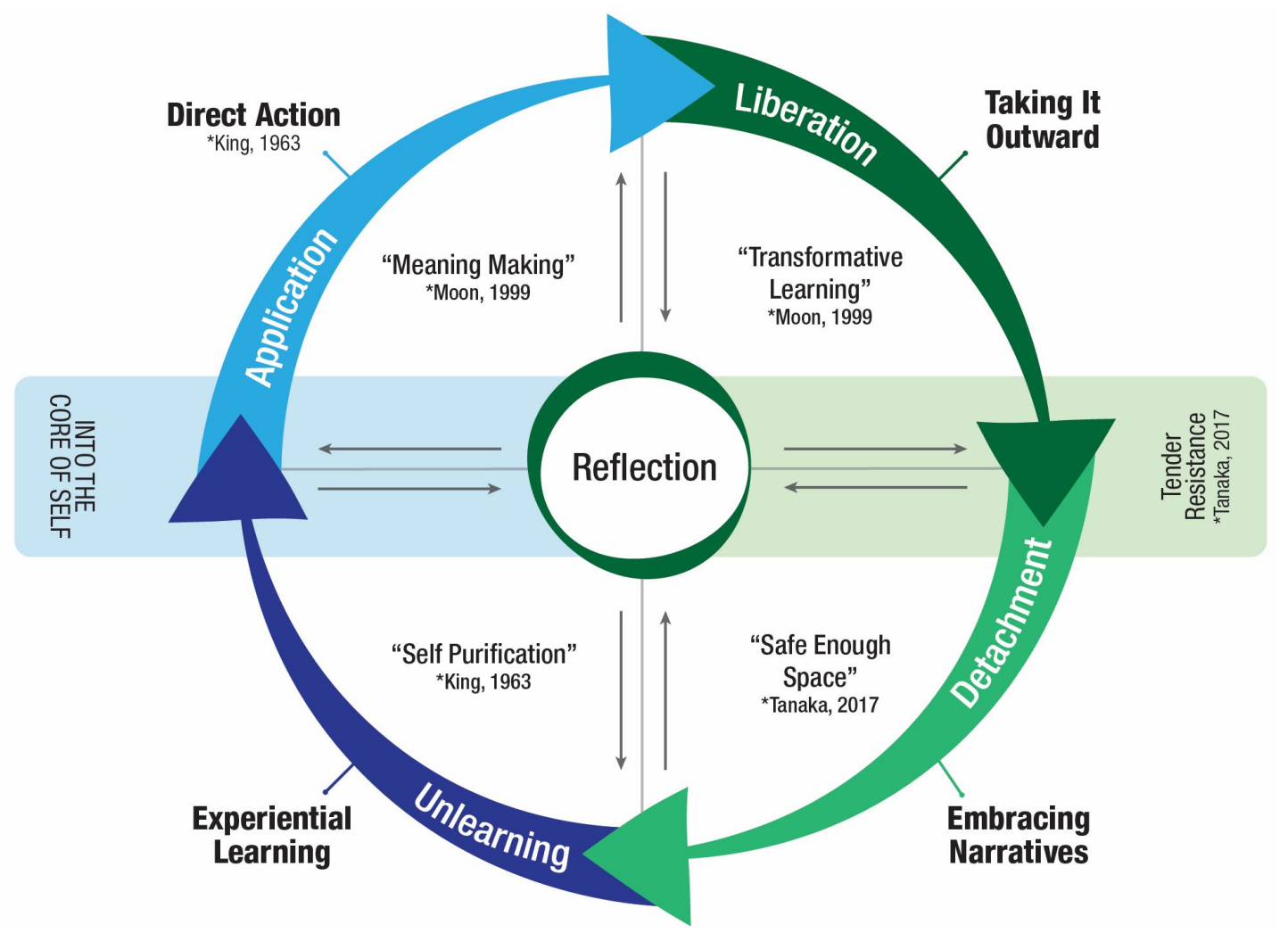

Pipe \& Stephens, 2019, 2021; Stephens \& Pipe, 2020

Synthesizing the common philosophical principles present across the strands of social justice education (see Adams, 2016; Hytten \& Bettez, 2011), the TALLS model provides a framework for reflective and active learning that disrupts colonizing teaching and learning practices even while operating within colonizing educational structures and systems. Through backward design that intentionally incorporates student centered approaches to asset-based trust and community building (Tanaka, 2017; Yosso, 2006) and scaffolded processes of meaning making through reflection (Moon, 1999; 2001; 2004) and direct action (King, 1963) to intentionally address issues of power (Mignolo \& Walsh, 2018; Okun, 2016), the use of the TALLS model in course design charts a course for engaging learners in a process for developing their own critical consciousness.

\section{Addressing Power}

Because the history of American higher education is rooted in exclusivity initially developed for White Christian men (Thelin, Edwards, \& Moylen, 2013; Todd, 2018), certain knowledge, producers of knowledge, and modes of delivering knowledge have been privileged historically in higher education pedagogy and curriculum. Therefore, any attempt to design courses with an eye toward justice that meet the needs of today's students must begin with examination of power. The use of the TALLS model in course design works through backward design by interrogating the student learning outcomes, assessments, and learning activities in light of the Colonial Matrix of Power (Mignolo \& Walsh, 2018) and White 
supremacy/power-over culture (Okun, 2016). Drawing from the work of Quijano (2000) on coloniality in Latin America, Mignolo and Walsh's (2018) Colonial Matrix of Power outlines a process of colonization propped up by privileged knowledge and subjectivity, how the economy is structured, how authority is derived, and how gender and sexuality are defined. In higher education, interrogating power and privilege in pedagogy and course design means beginning with knowledge and subjectivity, which, in traditional colonizing form, invalidates the knowledge and ways of knowing of marginalized peoples. The colonization process is produced and reproduced in disciplinary standards and the affirmation that singular ways of validating knowledge exist, which is compounded by the academy's affirmation and reproduction of White supremacy/power-over culture. The TALLS model in course design calls for interrogating course outcomes, assessments, and activities for reinforcement of White supremacy culture (e.g., perfectionism, power hoarding, sense of urgency, quantity over quality, paternalism, defensiveness, worship of the written word, belief in one right way, either/or thinking, fear of open conflict, individualism, belief that I'm the only one (who can do this right), belief in objectivity, and claiming a right to comfort; Okun, 2016) and working intentionally to disrupt the examples of power-over culture in the course design or at least making transparent the power-over culture that is not easily addressed (e.g., the sense of urgency that comes within the boundaries of quarters or semesters).

\section{Trusting the Learner}

Backward course design through the TALLS model also considers student learning outcomes, assessments, and learning activities through an understanding that students have their own past learning journeys with variable future learning journeys. Using Tanaka's (2017) concepts of "trusting the learner" and "tender resistance," TALLS course design leaves intentional space in course outlines, activities, and assessments for surfacing past and present challenges and traumas while moving toward a forward-focused call to action. This past, present, and future is considered within the context of students' strengths and cultural capital (e.g., aspirational capital, familial capital, social capital, navigational capital, resistance capital, and linguistic capital; Yosso, 2006). By designing courses with a focus on the whole learner and the wealth of knowledge students bring to the learning space, educators accept learning as a nonlinear process in which students reflect and make meaning and connections throughout a course, revisiting content and concepts multiple times in multiple ways.

\section{Making Meaning}

Such a circular process of meaning making and reflection requires intentional scaffolding to support students as they engage in increasingly complex forms of reflection and action. In backward course design through TALLS, educators consider the types of scaffolded reflections and direct action needed to achieve the desired learning outcomes. Working backwards through Moon's $(1999 ; 2001 ; 2004)$ framework for reflection and experiential learning and King's (1963) principles of nonviolence, educators consider the types of transformative reflection and action that can move students from current understandings entering the course to new ways of thinking and acting for change. Considering how students might get to that transformative learning, course design also needs to attend to how students might link previous knowledge/ideas and experiences for working with meaning (Moon, 1999; 2001; 2004). To make these connections, students will need to recognize that some meaningful connection exists - what Moon (1999; 2001; 2004) calls making meaning - after first engaging with the material (or making sense) and noticing an idea without connection to prior knowledge. As reflection becomes more sophisticated, students need opportunities for information gathering, to educate others, to demonstrate personal commitment, to participate in increasingly applied experiential activities that require negotiation through circumstances and with others, and to take direct action and seek reconciliation of ideas or in relation to others (King, 1963). 


\section{AN EXAMPLE OF TALLS COURSE DESIGN: NATIVE MOVEMENT}

The authors developed a new course through the TALLS model (Pipe \& Stephens, 2019, 2021; Stephens \& Pipe, 2020) in fall 2019. The course was taught in spring 2020 but was disrupted in March 2020 by a rapid move to online learning due to the COVID-19 pandemic.

The course, Native Movement: Physical Activity in Native Communities, was developed for the institution's general education program aimed at first- and second-year students. The course operated in the social and behavioral sciences focused on non-Western societies. Therefore, the course was required to meet three standardized learning outcomes but was allowed additional outcomes to address the course topic and theme. The initial standardized outcomes were:

1. Interpret or evaluate information on diverse cultures.

2. Describe interconnections among cultures, polities, and/or intellectual traditions of the world other than the dominant Euro-American ones.

3. Use diverse cultural frames of reference and alternative perspectives to analyze issues.

The creation of course-specific outcomes allowed for the standardized outcomes to be addressed within the context of the subject matter. The course-specific outcomes were:

1. Examine Indigenous Ways of Knowing in physical activity for Native communities in the United States and Canada.

2. Analyze the impact of colonial power on the health of Native communities in the United States and Canada.

From the stated learning outcomes, a traditional backward design model was utilized (Wiggins \& McTighe, 1998 , 2005) for the development of initial assessments, readings, and learning activities. A course design alignment chart was developed for this initial stage of course design. However, the backward design approach only addressed the learning outcomes, not fully addressing justice-forward practices or equitybased teaching practice. Therefore, the authors utilized the TALLS model (Pipe \& Stephens, 2019, 2021; Stephens \& Pipe, 2020) in the process of outlining and organizing delivery of course content. This shifted the course away from the chronological timeline-based approach (pre-European contact, post-European contact, modern era) to a scaffolded approach of concepts and application opportunities.

\section{Taking Backward Design in New Directions}

Backward design creates a foundational scaffold for course development; however, the aim of the Native Movement course was to move from Westernized mindsets of stock learning to a justice-forward approach that highlighted multiple ways of knowing and thinking. This required that an expanded course design process be taken, which included a series of questions based in the TALLS model. First, in order to have difficult and deep conversations, what care needs to be established to protect students while promoting growth? Second, given the potential population of learners, how far and deep should the course content go? Third, in course planning, what teaching and learning behaviors need to be role modeled, explained, and examined? Fourth, how can the course be designed with student decision-making and flexibility at the forefront? Fifth, what voices are present or need to be present for this course to achieve course aims?

Each question taken individually could be seen as established practice when creating a course. However, when taken together, the questions create an operationalized approach for challenging established practice. Practice is further challenged when these questions are asked in tandem through the lens of the TALLS model.

\section{In Order to Have Difficult and Deep Conversations, What Care Needs to Be Established?}

This question cannot be fully answered without the remaining questions being considered. Though traditional social justice and culturally responsive approaches are used, the TALLS model requires that the instructor think about what this means in terms of course aim and context. For the Native Movement course, the content pulled heavily from Indigenous knowledge systems related to health and concepts of wellness. This required that care for the student and by the student be established within the context of those systems. The establishment of a community agreement, designed by the students, was central—-though only 
foundational - to this approach. The course would require early focus on key concepts from Indigenous knowledge systems and continuous reinforcement in order for care of the learner and care of the content to be upheld. This included early explorations of the Learning Spirit (Battiste, 2010), operating from a place of "trust in the learner" (Tanaka, 2016), and de-emphasizing and naming of the Colonial Matrix of Power (Mignolo \& Walsh, 2018; Quijano, 2000). Students would need continuous opportunities to provide feedback on their learning experiences and needs. The instructor would need to continuously plan on reinforcing these new approaches to learning even if met with student resistance.

\section{Given the Potential Population of Learners, How Far and Deep Should the Course Content Go?}

This question is often the first one asked and answered by the instructor. However, with TALLS, this question is asked continuously throughout the planning and delivery of the course. It should be guided by the learning outcomes and learner curiosities equally, which means it cannot be answered fully before the course is taught. For example, the Native Movement course was initially designed under the assumption that the students would complete the first two quadrants of the TALLS model (academic detachment and unlearning). This changed once the students began moving through the course and offering ongoing feedback. The feedback demonstrated a clear desire to move into application. The course design had to be agile enough to meet learner desires and curiosities, while addressing the course learning outcomes.

\section{In Course Planning, What Teaching and Learning Behaviors Need to Be Role Modeled, Explained, and Examined?}

This question is essential for establishing clarity and transparency for the learners in the space. The course, by nature of the topics and design, will challenge established student understandings of classroom management, learning norms, and evaluation. Therefore, specific attention to the intention of teaching and learning behaviors is not only needed but essential to establishing a safe enough space for learners to dive deeply into curiosity and exploration. For example, in the design of the Native Movement course, the Colonial Matrix of Power (Mignolo \& Walsh, 2018; Quijano, 2000) was presented to the students in the first week. By walking through the impact of the Matrix and allowing students space to share their own impressions and experiences with learning within the context of the Matrix, the students were more open to teaching and learning methods that would normally be considered challenging (observation notes, January 23, 2020).

How Can the Course Be Designed With Student Decision-Making and Flexibility at the Forefront?

As previously noted, flexibility is essential for including learner curiosities as a central focus for the course. Flexibility can take multiple forms throughout the course, such as providing students with options for directing course content through reading choices, topic choices, and opportunities to teach content. Additionally, providing students with choice in assignment modality creates opportunities for learners' curiosities to take shape and be explored. In the Native Movement course, this flexibility created an academic confidence for exploring content independent of the faculty member. Around the third week of the course, the faculty member canceled a class meeting due to illness; however, the students chose to hold class without the faculty member and explore the content and assignments as a group (observation notes, February 4, 2020).

\section{What Voices Are Present or Need to Be Present for This Course to Achieve Course Aims?}

Each academic discipline ascribes to a traditional canon of texts and authors that are considered foundational to the field. This approach often reproduces traditional disciplinary philosophies and boundaries that reinforce the very colonizing practices that the TALLS model seeks to disrupt. Therefore, in course design, it is essential to consider why specific texts are central to the canon. For the Native Movement course, a blend of literature from kinesiology and sociology were considered, both of which have traditional canons built on White, Western approaches to learning. When considering why these texts are repeatedly used, it becomes clear that a shared understanding about the foundational principles governing each field was the aim. Therefore, meeting these same aims becomes possible by finding alternative texts 
and approaches from different and more representative scholars. In terms of the Native Movement course, the work of Joseph Oxendine (Lumbee; 1994) on Native concepts, histories, and philosophies of sport and games, along with Heidi Altman and Thomas Belt's (Eastern Band Cherokee; 2009) coverage of Cherokee understandings of health and well-being, were used to provide the same foundations of the canon but with an eye toward expanding valued ways of knowing. In particular, for the Native Movement course, it became evident that every text, material, and learning example needed to be evaluated through a similar process of investigating why an item was used and a critical reconsidering of what should be used. For this course, $75 \%$ of all materials used were created by Native scholars or by scholars working in direct partnership with Native communities. All other materials were presented with great transparency regarding their purpose and a deeper discussion around the materials' limitations and need for counter-narrative approaches. Students in the Native Movement course indicated that the intention behind selecting text was important. In their mid-course evaluations, students commented that "...all the readings have been spot on for what we need to know," and indicated that each text helped them expand their view of each concept (observation notes, March 19, 2020).

\section{Igniting Learning: TALLS and Course Delivery}

Design of a course is only part of the process; course delivery is the meat of the experience for the learner. In the TALLS model, learners are taken through a structured process of examining their own knowledge and experiences as key parts of a learning process. For the Native Movement course, delivery highlighted the importance of design decisions that reinforced a clear need to disrupt traditional approaches to canon, content delivery, and student engagement. By using the TALLS model to design the course, the faculty member was able to intentionally create adaptable choices into the process that allowed students to determine how the course would be delivered. This included introducing the students to concepts such as the Colonial Matrix of Power (Mignolo \& Walsh, 2018; Quijano, 2000), power-over culture (Okun, 2016), and the Learning Spirit (Battiste, 2010) within the first two weeks of the course. This empowered the students to think of the learning process differently with a shared commitment to disrupt the reproduction of colonized learning. Students were equally invested in reimagining the learning space to embrace their own curiosity. In reflections on their individual Learning Spirit, students indicated that they enjoyed communal learning experiences, the opportunity to author and apply content, and a mix of modalities that reinforce learning and create space for "playing with" concepts.

The opportunity to examine and reimagine what learning could look like started early with the students' creation of a community agreement. The students were given a primer constructed from the work of Claude Steele, that asked them to imagine a learning space where they could ask each other anything. The students outlined a space that included "patience as we learn new histories and unlearn others," "assuming positive intent with courage to name harms," "[being] mindful of differences through not discrediting one another and valuing our different learning spirits," and "[being] accountable to the future, and not responsible for an unchangeable past" (observation notes, February 11,2020). This community agreement set the tone for the course and the shared learning environment and purpose.

These shared ideals were present in multiple class activities but were especially evident in an activity exploring the Dickinson College digital archives for the Carlisle Indian School. Students were split into pairs and asked to critically read through the archives. Students were allowed to follow their own interests and curiosities throughout the collection. Some students explored their own ancestral connections, while others looked at connections to sport, reviewed student records, and analyzed others' images of students at Carlisle. The students then returned to the larger class to discuss their findings. The discussion uncovered the students' desire to make sense of why education in the United States is structured the way it currently operates. They found parallels between the boarding school approach and the crisis occurring at the US/Mexico border in 2019/2020. The students were able to deeply examine their own personal beliefs and values related to learning, while challenging each other to imagine the lasting impacts of boarding schools on Indigenous communities.

The structured flexibility of the course actually created unexpected opportunities. For example, the mid-course evaluations revealed the students' desire to move from experiential learning (the second 
quadrant of TALLS) and into application (the third quadrant). The course itself was not designed with the thought that students would be ready to move to application in a semester. However, the students echoed a strong desire to visit local Native communities, museums, and Powwows. The students wanted more opportunities to take their learning outward and bring the texts and concepts to life. This shift from passive engagement with content to active exploration was a powerful experience to witness. TALLS allowed the students to boldly name what they needed to best engage the course content and purpose.

\section{CONCLUSION}

When constructing and designing a course, the TALLS model for developing critical consciousness provides a structured reimagining of traditional backward design. Starting with a clear understanding that both the course learning outcomes and student curiosities should be equally valued in directing the course, the design of the course and assessments should be developed with intentional options for student curiosity to shape and direct the process. The initial step of course design should be to begin with a critical reflection on course learning outcomes and their ability to meet the needs of diverse ways of knowing. By examining course learning outcomes through the lenses of the Colonial Matrix of Power (Mignolo \& Walsh, 2018; Quijano, 2000) and power-over culture (Okun, 2016), instructors and course designers can ensure that learning outcomes set the landscape for a course that is responsive to diverse student needs and seeks to decolonize Western educational approaches.

Following backward design (Wiggins \& McTighe, 1998, 2005), critically examined course learning outcomes lead to robust course assessment and evaluation options that can accommodate multiple ways of knowing and an asset-based learning approach. Creating opportunities for student choice in modality and content can create engaged critical learners. From the assessment and evaluation options, the course activities can be constructed through the lens of the TALLS-based approach that emphasizes student care, student agency, and justice-forward application. TALLS shapes a critically reflective review of content, student engagement, and traditional Western academic values. This reflective review creates space for transparent learning choices that engender student confidence in their ability to examine their curiosities from a critical scholarly perspective.

By answering key questions developed from the TALLS model, instructors and course designers can create a course that is responsive to student curiosities, needs, and perspectives without compromising rigor. The instructor or course designer should ask five key questions: (1) In order to have difficult and deep conversations, what care needs to be established to protect students while promoting growth? (2) Given the potential population of learners, how far and deep should the course content go? (3) In course planning, what teaching and learning behaviors need to be role modeled, explained, and examined? (4) How can the course be designed with student decision-making and flexibility at the forefront? and (5) What voices are present or need to be present for this course to achieve course aims? These questions intentionally create room for learners to share in the process of directing the course and achieving outcomes.

\section{REFERENCES}

Adams, M. (2016). Pedagogical foundations for social justice education. In M. Adams \& L.A. Bell (Eds.), Teaching for diversity and social justice (3rd ed., pp. 27-53). New York, NY: Routledge.

Battiste, M. (2010). Nourishing the Learning Spirit: Living our way to new thinking. Education Canada, $50(1), 14-18$.

Bowen, R.S. (2017). Understanding by design. Vanderbilt University Center for Teaching. Retrieved from https://cft.vanderbilt.edu/understanding-by-design/

Higher Education Curriculum. (n.d.). In Education encyclopedia-StateUniversity.com. Retrieved from https://education.stateuniversity.com/pages/1895/Curriculum-Higher-Education-

TRADITIONAL-CONTEMPORARY-PERSPECTIVES.html

Hytten, K., \& Bettz, S.C. (2011). Understanding education for social justice. Educational Foundations, $25(1-2), 7-24$. 
King, M.L. (1963). Why we can't wait. Boston, MA: Beacon Press.

Mignolo, W., \& Walsh, C. (2018). The conceptual triad: Modernity/coloniality/decoloniality. In W. Mignolo \& C. Walsh (Eds.), On decoloniality: Concepts, analytics, praxis (pp. 135-152). Durham, NC: Duke University Press.

Mintz, S. (2020, September 3). Pedagogy and course design need to change. Here's how. Inside Higher $E d$. Retrieved from https://www.insidehighered.com/blogs/higher-ed-gamma/pedagogy-andcourse-design-need-change-here $\% \mathrm{E} 2 \% 80 \% 99$ s-how

Moon, J. (1999). A handbook of reflective and experiential learning: Theory and practice. London, UK: Routledge Falmer.

Moon, J. (2001). PDP working paper 4: Reflection in higher education learning. LTSN Generic Centre. Retrieved from https://www.brandeis.edu/experientiallearning/currentpdfs/reflectioninhighered.pdf

Moon, J. (2004). A handbook of reflective and experiential learning: Theory and practice. London, UK: Routledge.

Okun, T. (2016). White supremacy culture: Dismantling racism workbook (pp. 28-35). Retrieved from https://resourcegeneration.org/wp-content/uploads/2018/01/2016-dRworks-workbook.pdf

Pipe, L.M., \& Stephens, J.T. (2019). Curiosity as resistance: Pedagogical frameworks and principles of non-violence. Elon Teaching and Learning Conference, Elon, NC, USA.

Pipe, L.M., \& Stephens, J.T. (2021). Toward a Liberated Learning Spirit: A model for developing critical consciousness. Journal of the Scholarship of Teaching and Learning, 21(2).

Quijano, A. (2000). Coloniality of power, Eurocentrism, and Latin America. Nepantla: Views From South, 1(3), 533-580.

Stephens, J.T., \& Pipe, L.M. (2020). Justice-forward teaching: From detached learning to liberation. International Journal for Cross-Disciplinary Subjects in Education, 11(2), 4329-4334.

Tanaka, M. (2017). Learning and teaching together: Weaving Indigenous ways of knowing into education. Vancouver, BC: University of British Columbia Press.

Thelin, J.R., Edwards, J.R., \& Moyen, E. (2013, April 15). Higher education in the United States Historical development system. Retrieved from http://education.stateuniversity.com/pages/2044/Higher-Education-in-United-States.htm

Todd, K. (2018). Dreaming our way to new decolonial and educational futurities: Charting pathways of hope. In G.J. Sefa Dei \& C. Jaimungal (Eds.), Indigeneity and decolonial resistance: Alternatives to colonial thinking and practice (pp. 183-209). Gorham, ME: Myers Education Press.

Wiggins, G., \& McTighe, J. (1998). Understanding by design. Alexandria, VA: ASCD.

Wiggins, G., \& McTighe, J. (2005). Understanding by design: Second expanded edition. Alexandria, VA: ASCD.

Yosso, T. (2006). Whose culture has capital? A critical race theory discussion of community cultural wealth. Race Ethnicity and Education, 8(1), 69-91. 